\title{
Technology and Innovation in Agriculture: The Azores Case Study
}

\author{
https://doi.org/10.3991/ijim.v11i5.7070 \\ E.L.D.G.S. Silva $\left({ }^{\boxplus}\right)$ \\ Universidade dos Açores, CEEAplA, Angra do Heroísmo, Açores - Portugal \\ emiliana.ld.silva@uac.pt \\ C.M.M. Oliveira \\ SDASM, Ponta Delgada, Portugal
}

A.B. Mendes, H.M.G.F.O. Guerra

Universidade dos Açores, Algoritmi, Ponta Delgada, Portugal

\begin{abstract}
A growing population world might exceed its food supply in the future. Food availability needs an increasing agricultural productivity and production through technology and innovation. European concerns about innovation policies reflected on the Lisbon Agenda include the European program PROPRURAL + for the Portuguese Azores Islands. The agricultural innovation in the Azores started with the Green Revolution, which increased agricultural production, using seeds, fertilizers, chemical products and agricultural equipment. But much more innovation is needed for the Azores to became a wellsustained and competitive European region in this economic sector. For example, concerning milk, the region is responsible for more than $30 \%$ of the national production. But, since the liberalization in EU imposed by the global markets, a crisis in the sector is installed. Dairy producers are now facing many difficulties in trying to enhance the profitability of their farms, by reducing costs and improving efficiency. A characterization of the Azorean agriculture, emphasizing the milk production sector is presented. The specificities and the potential of the region are discussed and some agricultural innovations with IoT technologies are pointed out.
\end{abstract}

Keywords - technology; agriculture; robot; data mining

\section{Introduction}

Currently there are more than 7 billion inhabitants on planet Earth. In the next 10 years, it is estimated that the population will increase by more than a billion. Thus, inevitably the demand for food will increase in the near future and agriculture is at the center of the three challenges of the XXI century: climate change, depletion of natural resources, and food security [1].

All these factors demand a significant increase in agricultural productivity and production through technology and innovation. Innovation is the process of translating an 
idea or an invention into a good or a service that creates value or for which customers will pay. On the other hand, technology concerns the use of scientific knowledge to solve practical problems. To be innovative, the idea must be applied with an associated financial cost, and with the aim to satisfy a specific need.

Madureira et al. [2] present the innovative concept in agriculture and the branches of the innovation. According to these authors, innovation in Agriculture is the introduction of a new or significantly improved product (good or service), process, organizational structure or marketing method. Product innovation is defined by changes to its technical characteristics, with the offer of new features; focus on product quality or new ways of use / application. Process innovation is the introduction of a new or significantly improved production or delivery method, including significant changes in techniques, equipment or software. Organizational innovation is the introduction of a new structure or method of business organization or external relations. Finally, the marketing innovation occurs by introducing a new marketing method that involves significant changes in the design of the product or packaging. Marketing innovation is also about placing on the market or new ways of marketing, promotion or price.

There are several types of innovation: 1) technological innovation, 2) nontechnological innovation, 3) mixed innovation: with influence of the previous two. Finally, 4) hidden or soft innovation (non-technological origin, not linked to R\&D) and related to human resources, interactions and / or cooperation, and the role of various actors of innovation.

Madureira et al. [2] analyze the soft innovation in the Portuguese rural sector. Soft innovation is an important source of innovation in agriculture.

More than just a trend, innovation and new technology will be a need for sustainable and efficient agricultural production. The challenges ahead justify the increasingly arising companies to invest in this sector. Examples can be found in several Japanese companies, such as Panasonic, Toshiba, Sharp, Sony or Fujitsu, historically linked to electronics. Currently, those companies are experimenting in the production of strawberries in Dubai, in the production of lettuces in Japanese industrial complexes used in electronics manufacture or in the production of spinach in Singapore.

Therefore, it is necessary to clarify what is meant by these two so interlinked concepts in agriculture. Technology is associated with the creation of new products and / or new processes, while innovation is the introduction of technology in the agricultural reality. Given the paramount importance of innovation in agriculture we present the different types of innovation, giving special attention to hidden innovation and the innovation in the European policies (Lisbon Agenda). The particular case of the Azores is covered by means of the PROPRURAL + Community program [3].

In fact, the major innovation steps were named the Green Revolution and were based on technology introduction in agriculture to achieve higher productivity through the development of research in seeds, soil fertility, use of pesticides and mechanization including IoT [4,5]. Sensors and apps have a long history in agriculture, but recently their generalization became a competitive factor. Preoccupations with water consumption, soil improvement, species rotation, and animal growing can be addressed by IoT technologies in such a way that the term 
Smart Agriculture is becoming common sense. One example is the climate-smart agriculture (CSA), which is an approach for transforming and reorienting agricultural systems to support food security under the new realities of climate change [6].

New solutions for business challenges with machine-to-machine (M2M) communication are also in great demand in agriculture, and some of the most compelling IoT architectures and applications are coming from the agricultural industry. One example is the prototype mentioned by Schuster et al. [7], which puts forth an Internet-based architecture for machine-to-machine communication and computation that enhances bio-productivity in agriculture. The prototype utilizes an auxiliary language to enable data interoperability in a synthetic computing environment and to make connections between data and mathematical models. The approach also includes some aspects of cloud and context aware computing.

The rest of the paper is organized as follows: section II is devoted to explain in detail the main aspects relating to innovation in agriculture, suitable for application to the Azorean reality in the case study of section III; and also, to present an Azorean agriculture characterization based on the Census from 1998. Section III presents the Azorean case study of innovation concerning milk production. Finally, some conclusions and ideas for further work are presented in section IV.

\section{Innovation in European Union and Azores}

The world population is growing faster than the availability of food and this drives an increasing agricultural production and productivity through technology and / or innovation. The FAO projection of world population is 8.5 billion (2030); 9.7 billion (2050) and 11.2 billion (2100). In a global economic crisis situation, the food demand for a growing population imposes on global leaders the challenge of increasing agricultural production in a sustainable manner. As said by Hélder Muteia (FAO) in the workshop Demanda Mundial por Alimentos e o Combate à Fome, «it will not be easy. To answer this demand, global food production must grow by about $70 \%$.» This is a clear opportunity for innovation and technology.

Innovation is an EU fundamental bet since the 2000 Lisbon Agenda. There was recognition and appreciation of knowledge and innovation as drivers for competitiveness, sustainability, social cohesion and Europe 2020 maintain the goal of Agenda 2000. In the Azores islands innovation is promoted in the agricultural sector with the European program PRORURAL (+) - specially action 16, and Sub action 16.1 - Establishment and operation of operational groups of the European Innovation Partnership (EIP) for agricultural productivity and sustainability; Sub action 16.2 - Support for pilot projects and the development of new products, practices, processes and technologies; Sub action 16.3 - Cooperation between small operators with common process and sharing facilities and resources; Sub action 16.4 - Cooperation for development and promotion of short supply chains and local markets and Sub action 16.5 Intervention to mitigate and adapt to climate change and environmental projects and practices. 
In the agricultural field, innovation appeared with the Green Revolution [4,5] and associated with technological innovations for higher productivity through the development of research in seeds, soil fertilization, pesticide use and mechanization. The Green Revolution has enabled the development of appropriate seeds for specific types of soils and climates, soil adaptation for planting and development of machinery. The seeds have high resistance to different types of pests and diseases, its planting, combined with the use of pesticides, fertilizers, agricultural implements and machines, significantly increases agricultural production. There has been an extraordinary increase in food production. In Mexico, wheat has quadrupled its production in seven years.

Another example is the large increase in production and harvest in the Philippines rice. However, world hunger did not reduce, because food production in developing countries is aimed, mainly, for the industrialized rich countries such as the United States, Japan and the European Union. The modernization in the fields changed the agrarian structure. Small producers, who failed to adapt to new production techniques, could not achieve enough productivity to compete with big agricultural companies, and have requested large bank loans for the mechanization of activities. Their only form of payment is to sell the property to other producers. The Green Revolution provided technologies that achieve greater efficiency in agricultural production, significantly increasing food production. However, world hunger has not been resolved, edging out the humanitarian discourse to increase food production to end hunger in developing countries.

Innovation can also be acquired in the agricultural field through Data Mining techniques, using machine learning and statistical algorithms to extract patterns from data, which lead to new knowledge and better forecasts and decisions [8]. A well-known possible example is the production prediction using historical data obtained in agriculture in recent years.

Some of the Data Mining algorithms commonly used in agriculture are: 1) Supervised algorithms like some Artificial Neural Networks, Support Vector machines; and K-Nearest Neighbor algorithms; 2) Non-supervised algorithms (clustering) like: KMeans; Principal Component Analysis, Multiple Regression Model, Biclustering Techniques [8].

Ramesh and Vardhan [9] had estimated the crop production using two alternative methods (K-means clustering algorithm and regression model). They analyzed data from 44 years (1965 to 2009), using as dependent variable (target) rainfall, and independent variables: year, seeded area and production. The K-means algorithm found 4 clusters based on annual rainfall: cluster 1 - 1st 3 years, cluster 2 - with 21 years, cluster 3- with 18 years and cluster 4- with 2 years) As a result, they found similar average production between the real data and the models (linear regression and $\mathrm{K}$ means production). For instance, in cluster 3, the average production from actual data was 473,213, linear regression 469,635 and k-means algorithm 419,095. These results bear witness to the influence of climatic conditions (mainly rainfall). 
Table 1. Structural characteristic of Azorean Agriculture, Agricultural Census: 1989, 1999 and 2009.

\begin{tabular}{|c|c|c|c|c|c|}
\hline & & 1989 & 1999 & 2009 & Var \\
\hline 1. & $\begin{array}{l}\text { Average size agricultural } \\
\text { holdings (ha) }\end{array}$ & 4.8 & 6.3 & 8.9 & $\uparrow$ \\
\hline \multirow[t]{3}{*}{2.} & \multicolumn{5}{|c|}{ Indicators for community of farm typology } \\
\hline & i) Holdings number & 24,706 & 19,280 & 13,541 & $\downarrow$ \\
\hline & $\begin{array}{l}\text { ii) VPPT }(103 €) \text { of farms } \\
\text { specializing in livestock }\end{array}$ & n.a. & n.a. & 316,681 & -- \\
\hline
\end{tabular}

Table 2. Technological characteristic of Azorean Agriculture, according with Agricultural Census: 1989, 1999 and 2009.

\begin{tabular}{|c|c|c|c|c|c|}
\hline & & 1989 & 1999 & 2009 & Var \\
\hline \multirow[t]{4}{*}{1.} & Effective Animal & & & & \\
\hline & $\begin{array}{l}\text { i) No. of livestock per ha of SAU } \\
\text { in RAA }\end{array}$ & 1.43 & 1.72 & 1.71 & $\uparrow$ \\
\hline & $\begin{array}{l}\text { ii) Cattle (No. of animal/farm) by } \\
\text { exploration }\end{array}$ & 15.8 & 24.1 & 32.0 & $\uparrow$ \\
\hline & $\begin{array}{l}\text { iii) Dairy cows (No. of } \\
\text { animal/farm) }\end{array}$ & 10.3 & 19.3 & 28.2 & $\uparrow$ \\
\hline \multirow[t]{5}{*}{2.} & \multicolumn{5}{|l|}{ Indicators for farm machinery } \\
\hline & $\begin{array}{l}\text { i) No. of farms with farm } \\
\text { equipment and type of agricultural } \\
\text { machinery }\end{array}$ & 2,716 & 4,490 & 4,893 & $\uparrow$ \\
\hline & $\begin{array}{l}\text { ii) No. of tractors of farms and } \\
\text { classes of SAU }\end{array}$ & 1,899 & 2,630 & 3,750 & $\uparrow$ \\
\hline & $\begin{array}{l}\text { iii) No. of milking parlours of } \\
\text { farms and old milking parlours }\end{array}$ & n.a & n.a & 373 & - \\
\hline & $\begin{array}{l}\text { iv) No. of mobile milking machine } \\
\text { of farms and age of the machines. }\end{array}$ & n.a & n.a & 2,166 & - \\
\hline
\end{tabular}

Silva et al. [10] analyse the structural characteristics of the Azorean Agricultural sector, as seen in Table 1 and Table 2. The agricultural size of holdings has increased in the last 20 years, from 4.8 to 89 hectares and as a consequence, the number of holding has decreased. The normalized value of production was $316,681\left(10^{3}\right) €$.

The total number of animals (dairy cows and beef) has increased from 1989 to 2009 , as well the stock density (from 1.43 to 1.71 ). Farms with farm machinery increased from 2,716 to 4,893 (between 1989 and 2009) and the numbers of tractors are a big contribution, which increased from 1,899 to 3,750 (between 1989 and 2009).

For comparison purposes we use 1989 as the zero year for implementation of innovation in the Azores. Portugal joined the European Union in 1986, and at that time Portuguese agriculture was very "backward" with practically no agricultural equipment and the production systems were more extensive, less productive and with less specialized breeds.

Since then, and until Portuguese agriculture started using Community funds, a few years passed, and although we cannot say with certitude, in 1987 or 1988 there were 
no large funds to support agriculture. For these reasons, we considered the year 1989, from data published in the General Agricultural Census, as base year (year zero) without any "technological innovation".

The following years, and always taking advantage of Agricultural Census data (already published) corresponded to data that already includes technological innovation.

In São Miguel, Sampaio da Nóvoa [11] uses the work of [12] to evaluate the current technological evolution of the São Miguel agriculture, and concludes that the process of technological transformation at this time has a very positive economic impact on the income of producers. In fact, these authors confirm that producers greatly improved their competitive power and enhanced their economic viability in the context of the period. They also conclude that technological evolution is a function of the valuable work of experimentation and popularization, essential to the development of Azorean agriculture. For the authors in [11, 12] the main technological changes were: re-seeding of older and / or degraded pastures; rational scheme of fertilization; appropriate technologies for the conservation of silage. These authors also recommend cattle header control; generalization of artificial insemination; increased annual growth rate of herds; rational administration of concentrate; use of other energy sources (e.g. beet). Finally they indorse replacing whole milk for calf feeding; generalization of milking systems; accomplishment of crosses of cattle adapted to the productive vocation; and creation of efficient meat production systems that bring calves from birth to slaughter.

\section{The Case Study of Azores Innovation}

New technologies adopted by European farmers are the key to maintaining Europe competitiveness in the global market. However, these technologies are not accessible in the same way, the agricultural structure varying widely from country to country, from region to region. In effect, in the Member States of the European Union (EU) it varies as a function of differences in geology, topography, climate and natural resources, as well as diversity of regional activities, infrastructure and social customs [3].

There were about 12.2 million farms across the EU-28 in 2010, working 174.1 million hectares of land (the utilized agricultural area) or two fifths $(40.0 \%)$ of the total land area of the EU-28. The average size of each agricultural holding (farm) in the EU-28 was 14.2 hectares.

Milk production is the most important sector after cereal production, representing $12.7 \%$ of the agricultural activity in the EU-28. This sector is characterized by presenting a diverse structure in the EU Member States, both in terms of size of farms and dairy effective, and actual milk production. In 2013, total cow milk collection in the EU-28 amounted to about 141 million tonnes [3].

Regarding the Azores, this is a sector that has been expanding in some islands, especially in the island of São Miguel. 
Over the centuries, the Azores struggled with serious crises in the agricultural sector, leading to the introduction of new crops and new technologies. Presently, the region is again facing a new serious crisis, this time in the dairy sector.

The milk sector has been rising in some islands, especially in São Miguel island. Currently the region produces more than $30 \%$ of the national milk production. In spite of having witnessed a modernization of the sector in recent decades, the region struggles due to the small farm size and high fragmentation.

In the present scenario of milk production liberalization in Europe and competitiveness imposed by global markets, together with the effort that has been observed but that should be enhanced by the industry, producers who are forced to improve farm profitability have no alternative but to reduce costs and improve efficiency.

Today agriculture has a very distant reality from a relatively recent past. New technologies are increasingly emerging for the farm environment, and behind these technologies are engineers, scientists, biologists, technicians which directly or indirectly depend also on agriculture.

Thus, there are new tools that give producers a greater capacity for decision. But in the Azores specificity there are extra constraints, including the animal transhumance and insularity of the region, as well as the long distance to market and the poor literacy of farmers. The fact that cows remain in the pasture all year has limited somewhat the investment in these types of equipment.

Within the most relevant technologies that is possible to find in São Miguel farms, stand out modern management software, monitoring systems and video surveillance, pedometers for estrus detection, automatic feeders with individual metering of feed, separation curtains and milking process control. Some of this can be understood as IoT in the sense that pedometers or surveillance feed data to a system that can act on site and IP codes and cellular apps are frequently used.

Effective management software tools already have some expression. In the dairy farms, the daily, repetitive and cyclical interventions inevitably require records. Many of the farmers have this information recorded on paper, however this system makes it difficult to apply the concept of "Farm to Fork"screening, does not allow the issuing of alerts, hampers the processing of data and a more detailed analysis of available information.

A large range of effective management software tools are available in the market, some with the latest technology, consisting of web applications accessible from any computer, tablet or smartphone with internet access, without the need for software installation.

Some farms already have electronic identification systems (RFID) with various purposes, from the control of the feeding process, to assessing the supply of concentrates and balancing it with the cow individual nutrient needs. These stations have identification readers and when the animal approaches provide them concentrate according to the levels of production, the phase of lactation and regulate portions during the day, thereby reducing metabolic disorders (Figure 1).

Depending on the equipment available on the farm, the electronic identification of animals enables the control of the milking process with equipment that perform 
measurements of individual production (Figure 2), the exportation and the computer processing of the data collected. When animals are being treated, this information is recorded in the clinical history of the animals, the system preventing them from accidentally being milked, to avoid milk contamination in the cooling tank.

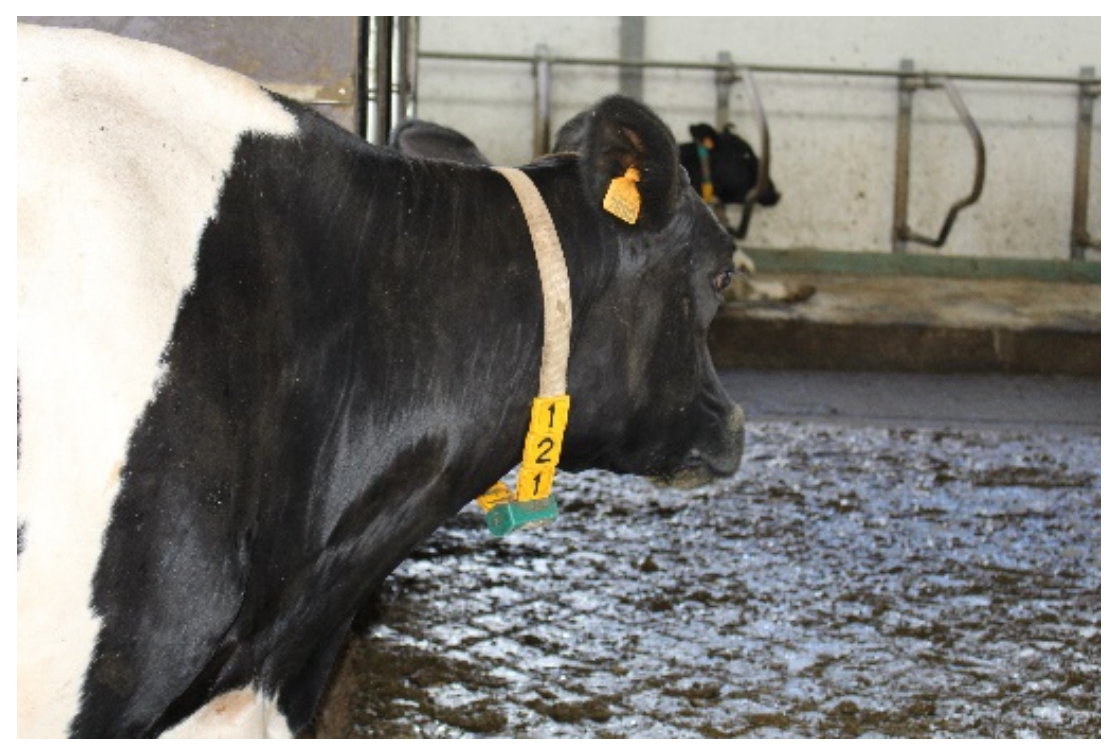

Fig. 1. Identification necklace with associated RFID chip

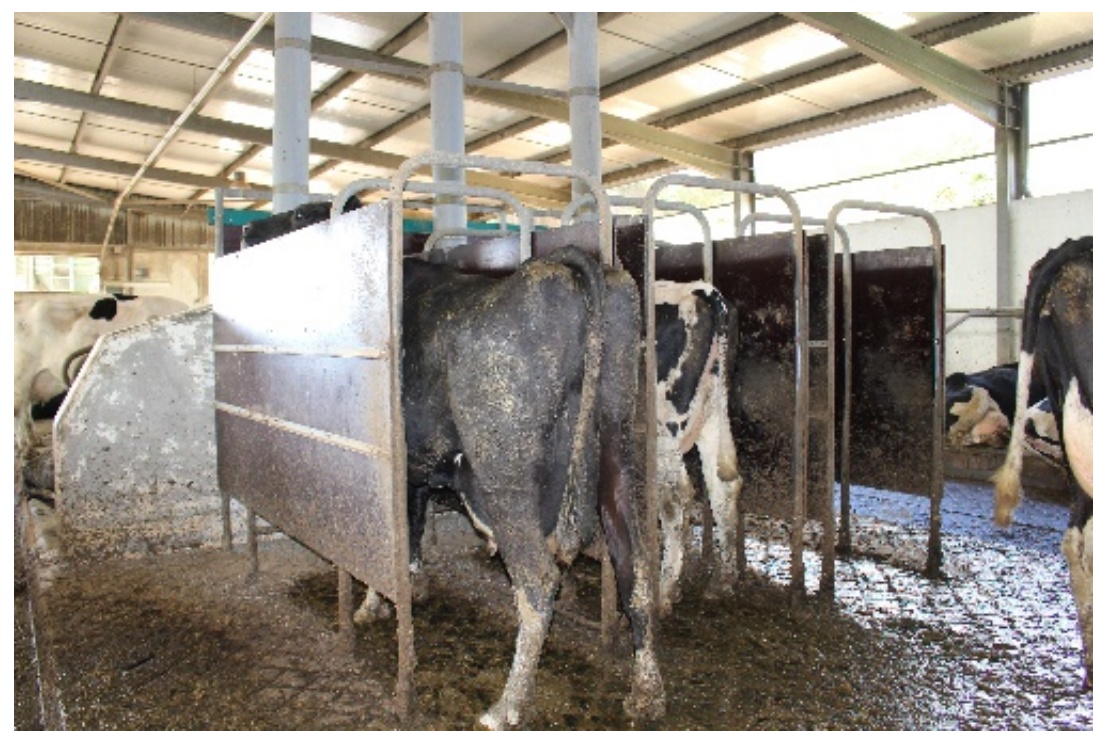

Fig. 2. Feeding Stations. 
There are also milking equipment that by measuring the electrical conductivity of milk enable the detection of mastitis and / or heats. More recently have come to São Miguel more sophisticated devices that detect the presence of blood in the milk, thereby preventing disease and eluding tank contamination (Figure 3).

The RFID tags are usually associated with the use of pedometers, electronic devices for assessing the activity of animals via the number of steps. Cattle has cyclic reproductive behaviour, and the number of steps increases past the point when the female rut, this information being transmitted to a central computer which analyzes the data and triggers alerts, thereby reducing hand labour with the observation of animals and improves reproductive efficiency, and in consequence the annual productivity.

The Rural Development Programmes of the Azores have enabled farmers to access EU funds and invest in the modernization of farms. In recent years, we have seen the construction of fixed stables and milking, on larger farms it is sometimes possible to find gates separating animals. It is an automatic system, controlled by software that allows the separation of animals for simple and stress-free intervention (Figure 4).

The Voluntary Milking System (VMS) is already a very common reality in the Portuguese mainland, and although there are producers who intend to adopt this system in the Azores, it is not yet to be found there, quite possibly because it is very expensive. In fact, a VMS requires specialized technical assistance, and above all, VMSs are applied on farms with different livestock management from the Azorean reality, requiring that the animals remain stabled 24 hours a day.

We believe that adopting a mid-term strategy it is possible to improve innovation in the Azorean agriculture, by developing new systems able to integrate the legacy systems and prepared to collecting and analyzing data generated by IoT devices, applying data mining techniques to provide efficient decision systems and, thus, contribute to help Azores to become a well-sustained and competitive EU region.

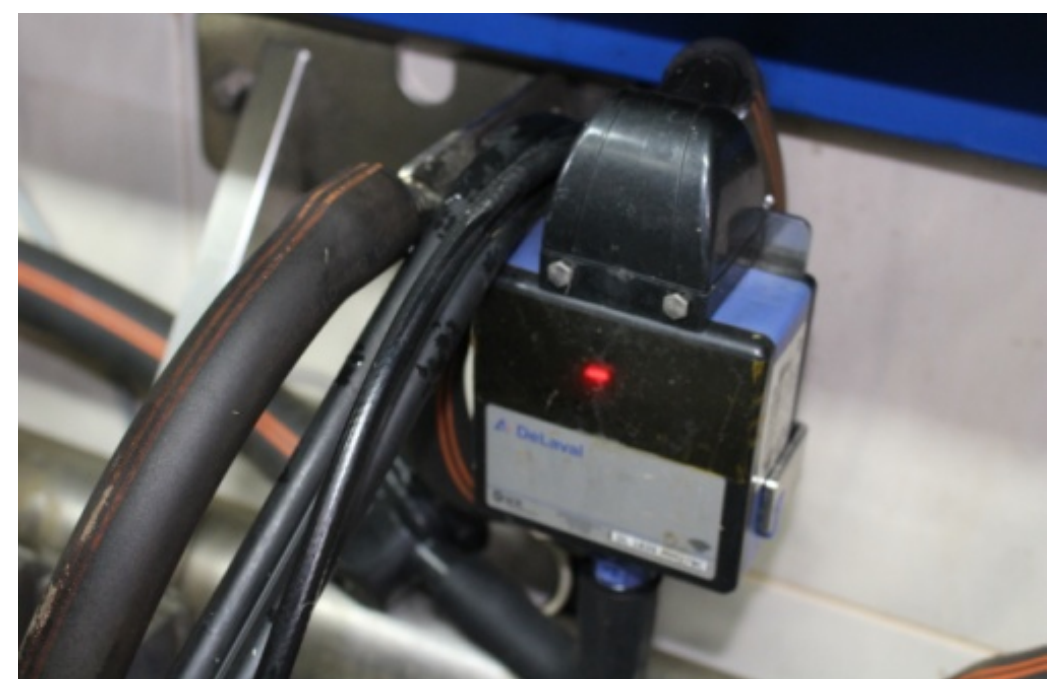

Fig. 3. Milk Meter Appliance. 


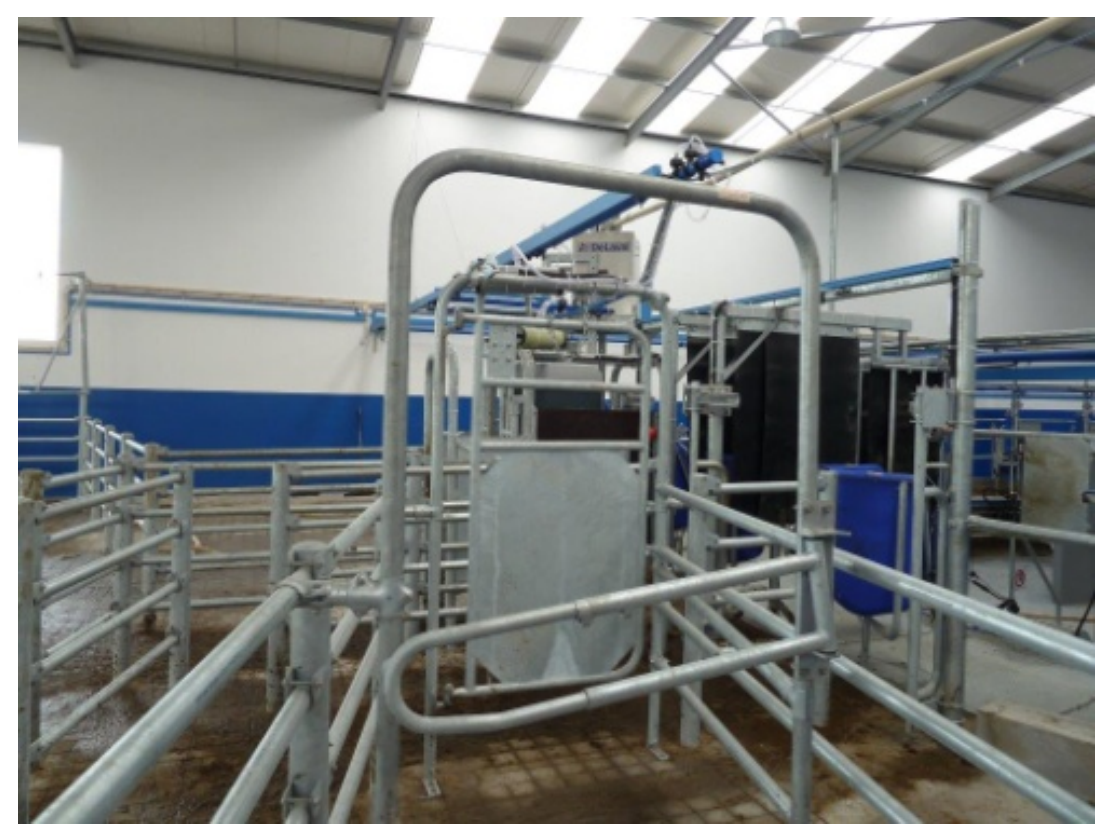

Fig. 4. Automatic gates for separating animals.

\section{Conclusion and Future Work}

Technology and innovation promote agricultural production and productivity, being a resource to be used for obtaining food and income to rural communities.

Data mining, although not much used in the agricultural field, presents a potential for the development of agricultural production and provides tools to support agricultural producer decisions, especially when coupled with IoT devices for data collection.

We propose to survey results on how well technology is accepted by Azorean farmers in following works.

\section{$5 \quad$ References}

[1] FAO "Global agriculture towards 2050" high-level expert forum, Roma 2-3 October 2009.

[2] Madureira, L., Gamito, T.M., Ferreira, D., Portela, J. "Inovação em Portugal Rural, Detetar, Medir e Valorizar", Principia, 2013, 200p.

[3] Eurostat Agriculture, forestry and fishery statistics Eurostat Pocketbooks, European Union, 2013. Available: http://ec.europa.eu/eurostat/documents/3930297/5968754/KS-FK-13001-EN.PDF/ef39caf7-60b9-4ab3-b9dc-3175b15feaa6

[4] FAO "Towards a New Green Revolution", in Report from the World Food Summit: Food for All. Rome 13-17 November 1996.

[5] Gaud, William S. "The Green Revolution: Accomplishments and Apprehensions". AgBioWorld., 8 March 1968. 
[6] Leslie Lipper "Climate-smart agriculture for food security" Nature Climate Change, vol. 4, pp. 1068-1072, 2014. https://doi.org/10.1038/nclimate2437

[7] Schuster, E.W.; Lee, H.-G.; Ehsani, R.; Allen, S.J.; Rogers, J.S.; "Machine-to-machine communication for agricultural systems: An XML-based auxiliary language to enhance semantic interoperability" Computers and Electronics in Agriculture Volume 78, Issue 2, X, pp. 150-161, September 2011.

[8] Hetal Patel and Dharmendra Patel "A Brief survey of Data Mining Techniques Applied to Agricultural Data” International Journal of Computer Applications Volume 95 - Number 9, 2014.

[9] Ramesh, D. \& Vishnu Vardhan, B., "Data Mining Techniques and Applications to Agricultural Yield Data", International Journal of Advanced Research in Computer and Communication Engineering, Vol. 2, Issue 9, September 2013, 3477- 3480.

[10] Silva, E., Jonnalagedda, S. and Marta-Costa, A., "The Efficiency of POSEI and PRORURAL Programs in Azores Islands Development" in IFSA 2016 - Symposium Workshop 5.3 Rural Development Policies in the Peripheral Southern and Eastern European Regions, 2016, U.K

[11] Sampaio da Nóvoa, Isabel C.B.L. 1992. Perspectivas de Evolução Tecnológica da Agropecuária Micaelense face à integração na Comunidade Económica Europeia (Óptica Económica). Relatório de Estágio do Curso de Engenheiro Agrónomo. Universidade Técnica de Lisboa, Instituto Superior de Agronomia. Lisboa.

[12] Avillez, Francisco (1991). Estudo de base microeconómica sobre as prespectivas do desenvolvimento da Agricultura dos Açores. Universidade Técnica de Lisboa, Instituto Superior de Agronomia. Lisboa.

\section{Authors}

E.L.D.G.S. Silva (corresponding author) is Assistant Professor in the Faculty of Agrarian Sciences and Environment, Azores University, Angra do Heroísmo. Açores, Portugal and a researcher in CEEAplA, Ponta Delgada, Açores, Portugal (e-mail emiliana.ld.silva@uac.pt).

C.M.M. Oliveira, is a Senior Technician in SDASM, the São Miguel Agrarian Services, Ponta Delgada, Açores, Portugal (e-mail: carloszootecnico@gmail.com).

A.B.Mendes is Assistant Professor in the Faculty of Sciences and Technology, Azores University, Ponta Delgada. Açores, Portugal and a researcher in Algoritmi Research Center, Minho University, Portugal (e-mail: armando.b.mendes@uac.pt).

H.M.G.F.O. Guerra is Assistant Professor in the Faculty of Sciences and Technology, Azores University, Ponta Delgada. Açores, Portugal and a researcher in Algoritmi Research Center, Minho University, Portugal (e-mail: helia.mg.guerra@uac.pt). 